\title{
LEVANTAMENTO TAXONÔMICO E FAUNA ACOMPANHANTE DE ALGAS DO COSTÃO ROCHOSO DE IRIRI, MUNICÍPIO DE ANCHIETA-ES
}

\section{Luan de Oliveira Cerqueira ${ }^{1}$ Annie da Silva Cassamali ${ }^{2}$ Erika Takagi Nunes ${ }^{3}$ Adriane Araújo Braga ${ }^{4}$}

Resumo: Em costões rochosos os substratos biológicos como as algas proporcionam importantes microhabitats para outros organismos. Este trabalho teve como objetivo realizar um levantamento das espécies de macroalgas presentes no costão rochoso da praia Costa Azul, Iriri, litoral sul capixaba bem como analisar a sua fauna acompanhante. Para isto, utilizou-se um quadrante de $10 \mathrm{~cm}^{2}$ lançado três vezes aleatoriamente na faixa onde localiza-se as algas e realizado a raspagem com auxílio de uma espátula. $O$ material coletado foi triado, contado e identificado. Coletou-se 11 espécies de algas, distribuídas nos filos Chlorophyta, com maior riqueza, Rhodophyta e Ochrophyta. Da fauna acompanhante, obteve-se três filos, cinco classes, onde Malacostraca foi a mais representativa, sendo os anfípodos com maior abundância. $O$ presente estudo contribuiu com o conhecimento da diversidade de macroalgas no costão de Iriri bem como a importância destes para abrigar e proteger a fauna acompanhante.

Palavras-chave: Macroalgas; Fauna associada; Microhabitats; Riqueza; Diversidade.

\footnotetext{
${ }^{1}$ Ciências Biológicas Licenciatura/Universidade Federal do Espírito Santo, Brasil. E-mail: luaano@hotmail.com. ${ }^{2}$ Ciências Biológicas Licenciatura/Universidade Federal do Espírito Santo, Brasil. E-mail: anniecassamali@hotmail.com.

${ }^{3}$ Departamento de Biologia/Universidade Federal do Espírito Santo, Brasil. E-mail: erikatnunes@gmail.com.

${ }^{4}$ Departamento de Biologia /Universidade Federal do Espírito Santo, Brasil. E-mail: dricrab@yahool.com.br.
} 